\title{
Vida Activa para una Buena Salud: Personas de la Tercera Edad $^{1}$
}

\author{
Jennifer Hillan and Anne Kendall ${ }^{2}$
}

Si usted piensa que la actividad física se limita a deportes estrenuos, actividades como clases de ejercicio, ipiense de nuevo! Lea para aprender por que la actividad física es importante y como puede empezar.

\section{¿Que es la Actividad Física y Porque es Importante?}

La actividad física es cualquier movimiento del cuerpo que usa energía, incluyendo actividades diarias como los quehaceres del hogar o arreglar el jardín, y caminar. La actividad física diaria ayuda a mantener el corazón, los pulmones, los huesos, los músculos, y las articulaciones

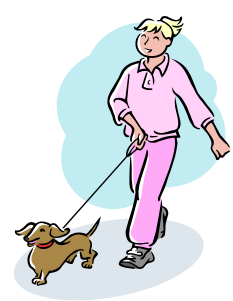
del cuerpo saludables y en buen funcionamiento. También ayuda a:

$\checkmark$ Incrementar el nivel de energía y el auto estima

$\checkmark$ Disminuir el estrés y la depresión.

$\checkmark$ Controlar el peso

$\checkmark$ Aumentar la fuerza y la flexibilidad

$\checkmark$ Controlar el dolor de artritis

$\checkmark$ Prevenir o retardar algunas enfermedades, como las enfermedades del corazón y la osteoporosis

$\checkmark$ Incrementar el balance y disminuir el riesgo de caídas
Ser activo puede ayudarle a mejorar su calidad de vida y ser independiente por más años.

\section{¿Cuantas y Que tipo de Actividades Necesito?}

Propóngase una meta de por lo menos 30 minutos de actividad, la mayoría de los días de la semana. La actividad moderada en intensidad no es estrenuante, pero debe incrementar suavemente su respiración y el ritmo cardiaco. Practique subiendo escaleras, caminando, o pasando la aspiradora.

Haga algunos ejercicios que requieran de esfuerzo 2 o 3 veces a la semana. Con músculos fuertes, usted podrá hacer mas cosas por su propia cuenta. No necesita adquirir unas pesas; también puede usar libros o una sopa enlatada!

Incluya ejercicios para el balance y la flexibilidad (estiramiento) como estos por lo

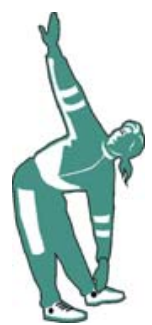
menos 2 veces a la semana. Estos le ayudaran a prevenir las caídas y a mantener el equilibrio de su cuerpo.

Ordene la guía de ejercicios gratuita que se encuentra en la página siguiente para ejemplos de fuerza, flexibilidad, y ejercicios de balance.

1. The English version of this Spanish document is Living Actively for Good Health: Older Adults (FCS8753). Este documento, FCS8753span, pertenece a una serie del Deparamento de Ciencias de la Familia, Juventud y Comunidad, Servicio de Extensión Cooperativo de la Florida, Instituto de Alimentos y Ciencias Agrícolas, Universidad de la Florida. Fecha de publicación: junio 2007. Favor de visitar el EDIS Web site en el http://edis.ifas.ufl.edu.

2. Jennifer Hillan, MSH, RD, LD/N, educadora/entrenadora, Departamento de Ciencias de la Familia, Juventud y Comunidad, y Anne Kendall, PhD, RD, LD/N, conferenciante, Departmento de Ciencia de Alimentos y Nutrición Humana, Servicio de Extensión Cooperativo de la Florida, Instituto de Alimentos y Ciencias Agrícolas, Universidad de la Florida, Gainesville, Florida 32611.

El Instituto de Alimentos y Ciencias Agrícolas es un empleador que provee Oportunidades Igualitarias, autorizado a proveer investigación, información educativa y otros servicios, únicamente a los individuos e instituciones que operan sin discriminación alguna con relación al credo, color, religión, edad, incapacidad, sexo, orientación sexual, estado civil, nacionalidad, opinión política o afiliaciones. Para más información sobre como obtener otras publicaciones de extensión, comuníquese con la oficina de Servicio de Extensión de su condado. Servicio de Extensión de la Florida / Instituto de Alimentos y Ciencias Agrícolas / Universidad de la Florida / Larry Arrington, Decano. 
Si la actividad física suena abrumadora no se desespere. Si usted no ha sido activo por un buen tiempo, comience lentamente y aumente su actividad gradualmente. Recuerde, ihacer algo es mejor que no hacer nada!

\section{Rompiendo Las Barreras}

No hay suficiente tiempo. Recuerde que la meta es hacer por lo menos 30 minutos de actividad durante el día. No tiene que ser todo de una vez.

$\checkmark$ Trabaje en el jardín en la mañana.

$\checkmark$ Trapee mientras ve la televisión.

$\checkmark$ Tome una caminata


corta después de la cena.

Muy aburrido. Escoja las actividades que usted disfrute e invite un amigo que las haga con usted. Varíe sus actividades y rutinas. Intente una trayectoria diferente.

No esta motivado. Cree una lista de metas realistas por un término corto y largo. ¡Prémiese asimismo

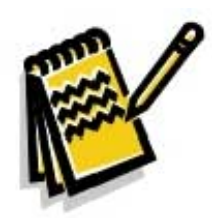
cuando las logre! Guarde un expediente de su actividad, así puede mirar que tan lejos ha llegado. ¡Encuentre un compañero de ejercicio!

No tiene suficiente energía. De hecho la actividad física aumenta su nivel de energía. Sea activo por 5 minutos y si está cansando, deténgase. ¡Pero es posible que se sienta con ganas de continuar!

\section{Consejos para Mantenerse Seguro}

Hágase un chequeo médico. La mayoría de las personas de la tercera edad deben ser cuidadosamente activas físicamente, no importa la edad o la condición. Sin embargo, tendrá que hablar con su proveedor de salud si:

- Usted tiene diabetes, enfermedades del corazón, u otra enfermedad crónica de salud

- Usted está en riesgo de contraer enfermedades del corazón

- Usted planea comenzar actividades vigorosas(actividades que lo hagan respirar y transpirar fuertemente)

Beba agua antes, durante, y después de una actividad.

Calentamiento y enfriamiento. Alguna actividad y estiramiento leves, antes y

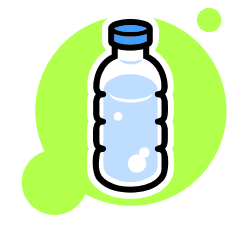
después de actividades de intensidad moderada, reduce el riesgo de lesiones.

Sea cauteloso. Dígale a alguien hacia donde va y cuando salga en las noches use prendas que sean visibles en la oscuridad.

\section{¿Cuanto es Demasiado?}

Su cuerpo le dirá si usted está haciendo demasiado. Ponga atención a los dolores tempranos y no se esfuerce demasiado, por que así la actividad dejara de ser agradable para usted. Busque consejos médicos si se llega a sentir mareado o sufre una lesión, dolores musculares o en el pecho.

Para una guía de ejercicio gratis del Instituto Nacional de Envejecimiento, llame al 1-800-222-2225 (numero gratuito) y pregunte por "Ejercicio: Una guía del instituto Nacional sobre el envejecimiento" o visite la pagina Web:

http://weboflife.nasa.gov/exerciseandaging/home.html.

Es fácil comenzar y hacer una actividad física regularmente, como un hábito que hace parte de la vida diaria. Hable con su proveedor de salud si lo necesita. 